\title{
The Transferrin Cycle and Clinical Roles of Citrate and Ascorbate in Improved Iron Metabolism
}

\author{
Aviva Levina* and Peter A. Lay* \\ School of Chemistry, University of Sydney, Sydney NSW 2006, Australia
}

\section{SUPPORTING INFORMATION}

\begin{abstract}
METHODS
Materials and Solutions. The following sources of proteins were used: (i) recombinant human TfR1 (CD71), extracellular domain (Cys89 - Phe760), (His)6-tagged at the $N$-terminus, from Sino Biological (Cat. No. 11020-H07H); (ii) human apo-Tf from Sigma (>98\% Tf; $\leq 0.005 \%$ Fe; Cat. No. T1147); (iii) human holo-Tf from Sigma ( $>98 \% \mathrm{Fe}_{2} \mathrm{Tf}$; Cat. No. T4132) (iv) bovine holo-Tf from Sigma (>98\% Fe 2 Tf; Cat. No. T1408); (v) bovine serum albumin (BSA, >99\%, Sigma Cat. No. A7638); and (vi) human serum (sterile filtered; Sigma Cat. No. H4522). Other reagents of highest available purity grade were from Sigma-Aldrich or Merck. Sterile solutions and plasticware used in cell culture were purchased from Life Technologies Australia. Water was purified by the Milli-Q technique. To minimize the influence of residual Fe(III) on Tf-TfR1 binding, buffer solutions used in BLI were treated with Chelex 100 chelating resin (Bio-Rad) for three days, while adjusting the $\mathrm{pH}$ values with solutions of ultra-pure $\mathrm{HCl}(0.10 \mathrm{M}$, Merck) or $\mathrm{NaOH}(0.10 \mathrm{M}$, Aldrich). The purified buffers were filtered through sterile $0.2 \mu \mathrm{M}$ Minisart RC membrane filters (Sartorius) prior to use.

Stock solutions of Fe(III)-NTA (NTA = nitrilotriacetic acid) or Fe(III)-citrate were prepared by mixing aqueous solutions of $\mathrm{Fe}\left(\mathrm{NO}_{3}\right)_{3} \cdot 9 \mathrm{H}_{2} \mathrm{O}$ with that of NTA (1:1.1 metal to ligand molar ratio) or citric acid disodium salt (1:2 metal to ligand molar ratio), and adjusting the $\mathrm{pH}$ value to $\sim 5.0$ with aqueous $\mathrm{NaOH}(1.0 \mathrm{M}){ }^{\mathrm{S} 1, \mathrm{~S} 2}$ The solutions were left to stand for at least a week at $295 \mathrm{~K}$, after which any formed insoluble $\mathrm{Fe}(\mathrm{III})$ hydrolysis products were removed using $0.2 \mu \mathrm{M}$ Minisart RC membrane filters. Precise Fe(III) concentrations in the filtrates were determined by GFAAS, using Agilent Technologies Series 200 spectrometer (equipped with Zeeman background correction), and certified Fe(III) standard (Aldrich Cat. No. 16596).

For most experiments, stock Tf solutions $(30 \mu \mathrm{M})$ were prepared in the binding buffer (20 mM HEPES, 25 mM NaHCO 3 , 140 mM NaCl, pH 7.4; where HEPES = 4-(2hydroxyethyl)piperazine-1-ethanesulfonic acid) ${ }^{8,9}$ and stored at $277 \mathrm{~K}$ for no more than a week. For the preparation of $\mathrm{Fe}_{2} \mathrm{Tf}$-oxalato stock solution, ${ }^{38,39}$ human apo-Tf $(30 \mu \mathrm{M})$ was dissolved in oxalate-containing binding buffer (20 mM HEPES, $25 \mathrm{mM} \mathrm{Na}_{2} \mathrm{C}_{2} \mathrm{O}_{4}, 140 \mu \mathrm{M}$ $\mathrm{NaCl}, \mathrm{pH} 7.40)$, mixed with $\mathrm{Fe}(\mathrm{III})-\mathrm{NTA}(100 \mu \mathrm{M})$, and reacted for $4 \mathrm{~h}$ at $310 \mathrm{~K}$. The resultant solution was stored at $277 \mathrm{~K}$ and diluted to [Tf] $=1.0 \mu \mathrm{M}$ with the same buffer immediately prior to BLI measurements. Concentrations of Tf and $\mathrm{Fe}$ (III) saturation in stock
\end{abstract}


solutions were determined by electronic absorption spectroscopy (Hewlett Packard Hp8452A diode-array spectrophotometer, spectral range, 200-800 nm; resolution, $2 \mathrm{~nm}$; integration time, $1 \mathrm{~s})$, using the following values of extinction coefficients: $\varepsilon(280 \mathrm{~nm})=8.4 \times 10^{4} \mathrm{M}^{-1}$ $\mathrm{cm}^{-1}$ for apoTf; $\varepsilon(280 \mathrm{~nm})=1.04 \times 10^{5} \mathrm{M}^{-1} \mathrm{~cm}^{-1}$ for Fe $2 \mathrm{Tf} ; \varepsilon(470 \mathrm{~nm})=4.9 \times 10^{3} \mathrm{M}^{-1} \mathrm{~cm}^{-1}$ for $\mathrm{Fe}_{2} \mathrm{Tf}^{\mathrm{S} 1, \mathrm{~S} 2}$

Bio-Layer Interferometry (BLI) Measurements. Protein-protein interaction studies were performed as described previously, ${ }^{28,31}$ using a single-channel BLItz instrument (ForteBio, Menlo Park, CA, USA) with a tube holder ( $250 \mu \mathrm{L}$ solution) at (295 \pm 1$) \mathrm{K}$ in Advanced Kinetics mode. The Ni(II)-NTA coated optical probes were supplied by ForteBio. The probes were loaded with TfR1 ( $4.0 \mu \mathrm{L}$ of $100 \mathrm{mg} \mathrm{mL}^{-1}$ in PBS) and re-used up to forty times (no more than twelve times in most experiments) after a single loading. Stock solutions of Tf (typically $1.0 \mu \mathrm{M}$ or $150 \mathrm{nM}$ ) in the binding buffer (20 mM HEPES, $25 \mathrm{mM} \mathrm{NaHCO}$, $140 \mathrm{mM} \mathrm{NaCl}, \mathrm{pH} 7.40)^{8,9}$ were prepared immediately before the experiments and used for Tf-TfR1 binding (step A in Figure 2, main text). The same buffer was used for the dissociation steps $\mathbf{B}$ and $\mathbf{D}$ (Figure 2), while typical endosomal buffer (step $\mathbf{C}$ ) ${ }^{11,19}$ was as follows: $100 \mathrm{mM}$ MES, $300 \mathrm{mM} \mathrm{KCl}$ (or $140 \mathrm{mM} \mathrm{NaCl}$ ), $0.10 \mathrm{mM}$ citrate (or other complexant, see main text), $\mathrm{pH}=5.60$. All the BLI data were background-corrected by performing the buffer-only runs with the same TfR1-loaded probe and the same experimental setting as for the Tf-TfR1 binding experiments. ${ }^{47}$ Processing of the data was performed using BLItz $^{\mathrm{S} 3}$ and Origin ${ }^{\mathrm{S} 4}$ software, and kinetic analyses were performed using ProKineticist ${ }^{\mathrm{S} 5}$ software. The initial BLI values of the association steps and the final values of the dissociation steps were set to zero for the kinetic analyses.

Cell Culture and Measurements of Tf Release. The HepG2 (human hepatoma) cells were originally received from the American Type Culture Collection (ATCC, Cat. No. HB-8065) and cultured in Advanced DMEM (DMEM = Dulbecco's modified Eagle's minimal essential medium; Thermo Fisher Scientific, Cat. No. 12491-015) supplemented with L-glutamine $(2.0 \mathrm{mM})$, antibiotic-antimycotic mixture $\left(100 \mathrm{U} \mathrm{mL}^{-1}\right.$ penicillin, $100 \mathrm{mg}$ $\mathrm{mL}^{-1}$ streptomycin and $0.25 \mathrm{mg} \mathrm{mL}^{-1}$ amphotericin B) and fetal calf serum (heat-inactivated; $2 \% \mathrm{v} / \mathrm{v})$. Cells were seeded at a density of $\sim 10^{5}$ cells per well of a 6 -well tissue culture plate (with $3.0 \mathrm{~mL}$ medium per well) and grown at $310 \mathrm{~K}$ in a $5 \% \mathrm{CO}_{2}$-humidified incubator to reach $\sim 60-70 \%$ confluence (the confluence of HepG2 cells is difficult to determine since they grow in clusters rather than in monolayers). The medium was then replaced with the treatment medium (3.0 mL per well), prepared from DMEM (Thermo Fisher Scientific, Cat. No. 11965-092), supplemented with L-glutamine (2.0 mM), antibiotic-antimycotic mixture, AlbuMax (fatty acid-rich bovine serum albumin, $1.0 \mathrm{mg} \mathrm{mL}^{-1}$; Thermo Fisher Scientific Cat. No. 11020021) and Fe(III)-citrate $(20 \mu \mathrm{M})$. Advanced DMEM was not used in this step, as it contains $\sim 100 \mathrm{nM}$ of human $\mathrm{Fe}_{2} \mathrm{Tf}^{45}{ }^{4}$ The treatment medium was sterilized by membrane filtration (using sterile $0.2 \mu \mathrm{M}$ Minisart RC membrane filters), added to growing HepG2 cells, incubated for $24 \mathrm{~h}$ at $310 \mathrm{~K}$ in a $5 \% \mathrm{CO}_{2}$-humidified incubator, then collected for the measurements of $\mathrm{Tf}$ release ${ }^{46}$ (cell debris were removed prior to the measurements by centrifugation for $2 \mathrm{~min}$ at $10,000 \mathrm{~g}$ and $295 \mathrm{~K}$ ). The resulting medium was used in step $\mathbf{A}$ of Tf cycle (Figure S4), while aqueous buffers (containing $2.0 \mathrm{mg} \mathrm{mL}^{-1} \mathrm{BSA}$ ) were used in 
steps B-D. Calibrations were performed by the addition of known concentrations of $\mathrm{Fe}_{2} \mathrm{Tf}$ into the same medium that was not exposed to HepG2 cells (Figure S4).

\section{RESULTS AND DISCUSSION}

Kinetic Analysis of Tf-TfR1 Binding and Determination of $K_{D}$ Values. Kinetic analyses of repeated scans using the same probe (Figure S3) showed no significant changes in $\mathrm{Fe}_{2}$ Tf-TfR1 binding affinity (measured by $K_{\mathrm{D}}$ values, Table $\mathrm{S} 1$ ) during the first twelve scans, while the affinity decreased about two-fold by the twenty-fifth scan. All the results reported in the main text were obtained using the first twelve scans at the same probe. Detailed results of kinetic analysis of $\mathrm{Fe}_{2}$ Tf-TfR 1 binding and dissociation (steps $\mathbf{A}$ and $\mathbf{B}$ in Figure 2, main text), performed by the serial dilution method (Figure 3 in the main text) , $^{8,9}$ are presented in Figures S5-S8 and in Table S1. Preliminary kinetic analyses using the Langmuir 1:1 binding model (Figure $3 a)^{6,8,47}$ were performed using smoothed experimental data in BLItz software, ${ }^{\mathrm{S} 3}$ while detailed analyses of the binding and dissociation steps were performed with ProKineticist software, ${ }^{\mathrm{S} 5}$ using the original non-smoothed data. Typical differences between non-smoothed and smoothed data sets are shown in Figure S5a, and fit residues for the both models are shown in Figure S5b,c.

The kinetic schemes used for fitting the step A were concentration-dependent (Figure S6 and Table S1). At the lowest protein concentrations (15.6 or $31.2 \mathrm{nM}$ ), good fits were obtained using a single first-order binding step (Figure S6a), while at $\left[\mathrm{Fe}_{2} \mathrm{Tf}\right]=62.5-250 \mathrm{nM}$, two sequential first-order steps were required (Figure S6b). The corresponding rate constants ( $k_{1}$ and $k_{2}, \mathrm{~s}^{-1}$ ) were linearly dependent on [ $\left.\mathrm{Fe}_{2} \mathrm{Tf}\right]$ across the studied concentration range, with $k_{2}$ being $\sim 5$-fold lower than $k_{1}$ (Figure S6d and Table S1). These data are in agreement with the 2:2 binding model accepted by most researchers, ${ }^{2,8-10}$ where binding of the first $\mathrm{Fe}_{2} \mathrm{Tf}$ molecule to TfR1 dimer is followed by the lower affinity binding of the second $\mathrm{Fe}_{2} \mathrm{Tf}$ molecule. At $\left[\mathrm{Fe}_{2} \mathrm{Tf}\right]=0.50-1.0 \mu \mathrm{M}$, an additional parallel low-rate binding step was required to fit the kinetic data (Figure S6c), but the corresponding rate constant $\left(k_{3} \sim 0.01 \mathrm{~s}^{-1}\right.$; Table S2) was independent of [ $\left.\mathrm{Fe}_{2} \mathrm{Tf}\right]$ (Figure S6d), which was attributed to non-specific binding of $\mathrm{Fe}_{2} \mathrm{Tf}$ to the probe. ${ }^{47}$ Note that the kinetics of the step $\mathbf{A}$ at $\left[\mathrm{Fe}_{2} \mathrm{Tf}\right]>125 \mathrm{nM}$ could also be fitted with two or three parallel first-order reactions, which would correspond to the independent binding of two $\mathrm{Fe}_{2} \mathrm{Tf}$ molecules to TfR1 dimer (2:1 binding model) ${ }^{2,8}$ but the fit residues were slightly higher than those for the sequential-parallel binding model (Figure S7).

The dissociation curves (step $\mathbf{B}$ in Figure 2) for $\mathrm{Fe}_{2} \mathrm{Tf}$ at $\mathrm{pH}=7.40$ were fitted with two parallel first order processes (Figure S8a and Table S1). The fast process (green line in Figure S8a, $k_{1} \sim 0.02 \mathrm{~s}^{-1}$, complete after $\sim 300 \mathrm{~s}$ ) corresponded to the dissociation of $\sim 5-6 \%$ of the total amount of $\mathrm{Fe}_{2} \mathrm{Tf}$ bound to the probe in step $\mathbf{A}$, which was consistent for all the $\mathrm{Fe}_{2} \mathrm{Tf}$ concentrations used (Table S1). The rest of the bound protein was removed in a slow process (blue line in Figure S8a, $k_{2} \sim 3.5 \times 10^{-4} \mathrm{~s}^{-1}, t_{1 / 2} \sim 2700 \mathrm{~s}$ ), which was also independent of $\mathrm{Fe}_{2} \mathrm{Tf}$ concentration applied in step $\mathbf{A}$ (Table S1). The fast dissociation process within the step B could be suppressed by the addition of excess Fe(III)-NTA $(0.10 \mathrm{mM})$ to the binding buffer, when the step B could be fitted with a single slow first-order process (Figure S8b). This result suggests that the fast dissociation effect was caused by the removal of apoTf or 
(mono)FeTf that were present at the probe at small proportions in an equilibrium with $\mathrm{Fe}_{2} \mathrm{Tf}$. Such removal shifted the equilibrium towards the formation of more Fe-depleted $\mathrm{Tf}$ on the probe. However, the addition of Fe(III)-NTA to the binding buffer resulted in fast deterioration of the probe (due to the dissociation of (His) 6 -tagged TfR1 that binds to metalNTA complexes), so it was not routinely used.

Based on the kinetic analyses of the steps $\mathbf{A}$ and $\mathbf{B}$, the dissociation constants for the binding of the first and second Tf molecules to TfR1 dimer (immobilized on a BLI probe) were calculated as follows:

$$
K_{\mathrm{D} 1}=[\mathrm{Tf}] k_{2}{ }^{\mathrm{B}} / k_{1}{ }^{\mathrm{A}}(1) ; \quad K_{\mathrm{D} 2}=[\mathrm{Tf}] k_{2}{ }^{\mathrm{B}} / k_{2}{ }^{\mathrm{A}}(2) .
$$

Equations (1) and (2) used the two main association rate constants $\left(k_{1}{ }^{\mathrm{A}}\right.$ and $\left.k_{2}{ }^{\mathrm{A}}\right)$, which were assigned to the sequential binding of two $\mathrm{Fe}_{2} \mathrm{Tf}$ molecules to TfR $1,{ }^{2,8-10}$ and only the second (slower) dissociation rate constant $\left(k_{2}{ }^{\mathrm{B}}\right.$ in Figure S7d, responsible for the dissociation of $>90 \%$ of $\mathrm{Fe}_{2} \mathrm{Tf}$ from the probe), which assumed that the dissociation rates of the two $\mathrm{Tf}$ molecules were undistinguishable. Application of these equations to the set of concentrationdependent $\mathrm{Fe}_{2} \mathrm{Tf}$ binding data at $\mathrm{pH}=7.40$ led to $K_{\mathrm{D} 1}=0.7 \pm 0.1 \mathrm{nM}$ and $K_{\mathrm{D} 2}=3.2 \pm 0.6 \mathrm{nM}$ (Table S1 and Figure $3 \mathrm{~b}$ in the main text), which was in an excellent agreement with the results of similar studies performed by SPR $\left(K_{\mathrm{D} 1}=0.61 \mathrm{nM}\right.$ and $K_{\mathrm{D} 2}=6.3 \mathrm{nM}$; or $K_{\mathrm{D} 1}=0.72$ $\pm 0.6 \mathrm{nM}$ and $\left.K_{\mathrm{D} 2}=4.1 \pm 1.4 \mathrm{nM}\right) .8$

Conditions of Fe Release in the Endosomal Step. Dissociation of Tf from TfR1 under endosomal conditions (100 mM MES, $300 \mathrm{mM} \mathrm{KCl,} 0.10 \mathrm{mM}$ citrate, $\mathrm{pH}$ 5.6) occurred in a single slow step $\left(k_{1} \sim 2 \times 10^{-4} \mathrm{~s}^{-1}\right.$, Figure S8c). This process was consistent with the slow dissociation of apoTf from TfR1 at $\mathrm{pH} 5.6$ (Figure S8d) ${ }^{8,9}$ By contrast, dissociation of Tf from TfR1 at pH 5.6 in the presence of 4.0 mM EDTA $^{11,19,28,31}$ included a fast step (Figure S8e, also visible in magenta line in Figure 4, main text). Decrease in BLI signal was also observed when the probes loaded with TfR1 only were incubated with the endosomal buffer (100 mM MES, $300 \mathrm{mM} \mathrm{KCl,} \mathrm{pH} \mathrm{5.6)} \mathrm{that} \mathrm{contained} 4.0 \mathrm{mM}$ EDTA, but not $0.10 \mathrm{mM}$ citrate (Figure 8f). Therefore, the effect of EDTA on the kinetics of step C (Figure S8e) was due to the partial removal of TfR1 from Ni(II)-NTA probe in the presence of a strong chelating agent, EDTA. These data confirm the advantage of using a natural Fe(III) chelating ligand, citrate, ${ }^{52,55}$ for the removal of $\mathrm{Fe}$ (III) from $\mathrm{Fe}_{2} \mathrm{Tf}-\mathrm{TfR} 1$ in the BLI model of Tf cycle.

Additional References (all the other reference numbers correspond to those in the main text):

S1. Aisen, P., Aasa, R., Malmstrom, B. G., and Vanngard, T. (1967) Bicarbonate and the Binding of Iron to Transferrin. J. Biol. Chem. 242, 2484-90.

S2. James, N. G., and Mason, A. B. (2008) Protocol to Determine Accurate Absorption Coefficients for Iron-Containing Transferrins. Anal. Biochem. 378, 202-207.

S3. $\quad$ BLItz Software, Version 1.1.ForteBio, Menlo Park, CA, USA, 2013.

S4. $\quad$ Origin Version 6.1, Microcal Origin, Northampton, MA, USA, 1999.

S5. ProKineticist, Version 1. Applied Photophysics, Leatherhead, UK, 1996. 
Table S1. Kinetic parameters of steps $\mathbf{A}$ and $\mathbf{B}$ of Tf cycle, and the determination of $K_{\mathrm{D}}$ values

\begin{tabular}{|l|l|c|c|c|c|c|c|c|c|c|c|}
\hline Step $^{a}$ & \multicolumn{1}{|c|}{ Param. $^{b}$} & \multicolumn{9}{|c|}{ Kinetic Curve $^{c}$} \\
\hline & & $\begin{array}{c}\text { Fig. S3b, } \\
\text { Scan 2 }\end{array}$ & $\begin{array}{c}\text { Fig. S3b, } \\
\text { Scan } 12\end{array}$ & $\begin{array}{c}\text { Fig. S3b, } \\
\text { Scan } 25\end{array}$ & $\begin{array}{c}\text { Fig. 3b } \\
1.0 \mu \mathrm{M}\end{array}$ & $\begin{array}{c}\text { Fig. 3b, } \\
0.50 \mu \mathrm{M}\end{array}$ & $\begin{array}{c}\text { Fig. 3b, } \\
0.25 \mu \mathrm{M}\end{array}$ & $\begin{array}{c}\text { Fig. 3b, } \\
0.125 \mu \mathrm{M}\end{array}$ & $\begin{array}{c}\text { Fig. 3b, } \\
62.5 \mathrm{nM}\end{array}$ & $\begin{array}{c}\text { Fig. 3b, } \\
31.25 \mathrm{nM}\end{array}$ & $\begin{array}{c}\text { Fig. 3b, } \\
15.6 \mathrm{nM}\end{array}$ \\
\hline $\mathbf{A}$ & $k_{1}, \mathrm{~s}^{-1}$ (seq.) & $4.1 \times 10^{-1}$ & $4.2 \times 10^{-1}$ & $3.6 \times 10^{-1}$ & $3.5 \times 10^{-1}$ & $2.2 \times 10^{-1}$ & $1.1 \times 10^{-1}$ & $5.6 \times 10^{-2}$ & $2.7 \times 10^{-2}$ & $1.2 \times 10^{-2}$ & $5.9 \times 10^{-3}$ \\
\hline & $k_{2}, \mathrm{~s}^{-1}$ (seq.) & $7.5 \times 10^{-2}$ & $7.9 \times 10^{-2}$ & $6.5 \times 10^{-2}$ & $8.4 \times 10^{-2}$ & $6.2 \times 10^{-2}$ & $2.5 \times 10^{-2}$ & $1.1 \times 10^{-2}$ & $4.2 \times 10^{-3}$ & -- & -- \\
\hline & $k_{3}, \mathrm{~s}^{-1}$ (par.) & $1.1 \times 10^{-2}$ & $1.1 \times 10^{-2}$ & $1.0 \times 10^{-2}$ & $1.3 \times 10^{-2}$ & $1.1 \times 10^{-2}$ & -- & -- & -- & -- & -- \\
\hline & $A_{1}, \mathrm{~nm}$ & 0.72 & 0.69 & 0.61 & 0.75 & 0.67 & 0.65 & 0.65 & 0.66 & 0.75 & 0.72 \\
\hline & $A_{2}, \mathrm{~nm}$ & 1.1 & 1.0 & 0.92 & 1.1 & 0.95 & 0.96 & 1.0 & 1.2 & - & -- \\
\hline & $A_{3}, \mathrm{~nm}$ & 0.28 & 0.24 & 0.19 & 0.25 & 0.27 & -- & -- & -- & -- & -- \\
\hline & $k_{1}, \mathrm{~s}^{-1}$ (par.) & $3.0 \times 10^{-2}$ & $2.6 \times 10^{-2}$ & $3.2 \times 10^{-2}$ & $1.9 \times 10^{-2}$ & $1.2 \times 10^{-2}$ & $1.6 \times 10^{-2}$ & $1.1 \times 10^{-2}$ & $2.2 \times 10^{-2}$ & $2.7 \times 10^{-2}$ & $2.4 \times 10^{-2}$ \\
\hline & $k_{2}, \mathrm{~s}^{-1}$ (par.) & $3.6 \times 10^{-4}$ & $3.5 \times 10^{-4}$ & $5.4 \times 10^{-4}$ & $3.0 \times 10^{-4}$ & $3.5 \times 10^{-4}$ & $2.8 \times 10^{-4}$ & $2.5 \times 10^{-4}$ & $2.7 \times 10^{-4}$ & $2.4 \times 10^{-4}$ & $2.2 \times 10^{-4}$ \\
\hline & $A_{1}, \mathrm{~nm}$ & 0.062 & 0.086 & 0.097 & 0.064 & 0.075 & 0.077 & 0.082 & 0.052 & 0.043 & 0.030 \\
\hline & $A_{2}, \mathrm{~nm}$ & 1.3 & 1.2 & 1.0 & 1.2 & 1.1 & 0.96 & 0.84 & 0.74 & 0.60 & 0.42 \\
\hline & $K_{\mathbf{D} 1}, \mathbf{n M}{ }^{d}$ & $\mathbf{0 . 8 9}$ & $\mathbf{0 . 8 4}$ & $\mathbf{1 . 5}$ & $\mathbf{0 . 8 6}$ & $\mathbf{0 . 7 9}$ & $\mathbf{0 . 6 6}$ & $\mathbf{0 . 5 6}$ & $\mathbf{0 . 6 1}$ & $\mathbf{0 . 6 4}$ & $\mathbf{0 . 5 7}$ \\
\hline & $\boldsymbol{K}_{\mathbf{D} 2}, \mathbf{n M}{ }^{d}$ & $\mathbf{4 . 8}$ & $\mathbf{4 . 4}$ & $\mathbf{8 . 3}$ & $\mathbf{3 . 6}$ & $\mathbf{2 . 8}$ & $\mathbf{2 . 7}$ & $\mathbf{2 . 9}$ & $\mathbf{4 . 0}$ & -- & -- \\
\hline
\end{tabular}

${ }^{a}$ Designations of the steps correspond to Figures 1a and 2 (main text). For the association step A, the initial BLI amplitude was set to zero for the kinetic analysis. For the dissociation step B, the final BLI amplitude was set to zero during the kinetic analysis. ${ }^{b}$ Designations of the parameters: $k_{\mathrm{i}}\left(\mathrm{s}^{-1}\right)$ are the rate constants of sequential (seq.) or parallel (par.) pseudo-firstorder reactions; and $A_{\mathrm{i}}(\mathrm{nm})$ are the amplitudes of changes of the BLI signals $(\Delta \lambda)$ in the corresponding steps. ${ }^{c}$ Kinetic data correspond to the experimental and fitted kinetic curves shown in Figure S3b and Figure $3 \mathrm{~b}$ (main text, numbers correspond to the $\mathrm{Fe}_{2} \mathrm{Tf}$ concentrations). ${ }^{d}$ Equilibrium constants for the sequential binding of two equivalents of $\mathrm{Fe}_{2} \mathrm{Tf}$ to TfR1: $K_{\mathrm{D} 1}=$ $\left[\mathrm{Fe}_{2} \mathrm{Tf}\right] \times k_{2}\left(\right.$ step B) $/ k_{1}(\operatorname{stepA}) ; K_{\mathrm{D} 2}=\left[\mathrm{Fe}_{2} \mathrm{Tf}\right] \times k_{2}\left(\right.$ step B) $/ k_{2}($ stepA) (see the discussion at pp. 3-5 and Figures S6-S8). All the measurements were performed at $(295 \pm 1) \mathrm{K}$. 
Table S2. Tf-TfR1 dissociation kinetics in step $\mathbf{D}(\mathrm{pH} 7.4)$ dependent on the conditions of step $\mathbf{C}$ ( $\mathrm{pH}$ 5.6)

\begin{tabular}{|c|c|c|c|c|}
\hline \multirow[t]{2}{*}{ Conditions $^{a}$} & \multicolumn{4}{|c|}{ Kinetic Parameters } \\
\hline & $\boldsymbol{k}_{\mathbf{1}}, \mathbf{s}^{-1}(\%)^{b}$ & $\boldsymbol{k}_{2}, \mathbf{s}^{-1}(\%)^{b}$ & $\boldsymbol{k}_{3}, \mathbf{s}^{-1}(\%)^{b}$ & $k_{\mathrm{Fe},} \mathbf{s}^{-1 c}$ \\
\hline \multicolumn{5}{|c|}{ Figure S9a: step C at $100 \mathrm{mM}$ MES, $300 \mathrm{mM} \mathrm{KCl,} \mathrm{pH} \mathrm{5.6,} 200 \mathrm{~s}, 0-4.0 \mathrm{mM}$ edta } \\
\hline (1) no edta & $1.36(7)$ & $0.11(3)$ & $1.1 \times 10^{-3}(90)$ & $3.6 \times 10^{-4}$ \\
\hline (2) $10 \mu \mathrm{M}$ edta & $0.89(30)$ & $9.6 \times 10^{-2}(9)$ & $8.5 \times 10^{-4}(61)$ & $1.8 \times 10^{-3}$ \\
\hline (3) $0.10 \mathrm{mM}$ edta & $1.64(56)$ & $0.22(18)$ & $1.2 \times 10^{-2}(26)$ & $4.1 \times 10^{-3}$ \\
\hline (4) $1.0 \mathrm{mM}$ edta & $1.45(69)$ & $0.33(22)$ & $6.1 \times 10^{-2}(9)$ & $5.8 \times 10^{-3}$ \\
\hline (5) $4.0 \mathrm{mM}$ edta & $1.65(58)$ & $0.32(30)$ & $6.5 \times 10^{-2}(12)$ & $4.3 \times 10^{-3}$ \\
\hline \multicolumn{5}{|c|}{ Figure S9b: step C at $100 \mathrm{mM}$ MES, $300 \mathrm{mM} \mathrm{KCl,} \mathrm{pH} \mathrm{5.6,} 200 \mathrm{~s}, 0-1.0 \mathrm{mM}$ citrate } \\
\hline (1) no citrate & -- & -- & $1.2 \times 10^{-3}(100)$ & -- \\
\hline (2) $1.0 \mu \mathrm{M}$ citrate & $1.0(20)$ & $0.12(11)$ & $3.7 \times 10^{-3}(69)$ & $1.1 \times 10^{-3}$ \\
\hline (3) $10 \mu \mathrm{M}$ citrate & $1.22(48)$ & $0.11(14)$ & $5.5 \times 10^{-3}(38)$ & $3.3 \times 10^{-3}$ \\
\hline (4) $0.10 \mathrm{mM}$ citrate & $0.87(79)$ & $5.6 \times 10^{-2}(21)$ & -- & $7.8 \times 10^{-3}$ \\
\hline (5) $1.0 \mathrm{mM}$ citrate & $1.0(76)$ & $8.2 \times 10^{-2}(24)$ & -- & $5.4 \times 10^{-3}$ \\
\hline \multicolumn{5}{|c|}{ Figure S9c: step $\mathbf{C}$ at $100 \mathrm{mM}$ MES, $300 \mathrm{mM} \mathrm{KCl,} \mathrm{pH} \mathrm{5.6,} 200 \mathrm{~s}, 0-1.0 \mathrm{mM}$ ATP } \\
\hline (1) no ATP & -- & -- & $1.2 \times 10^{-3}(100)$ & -- \\
\hline (2) $1.0 \mu \mathrm{M}$ ATP & $1.4(24)$ & $0.12(14)$ & $3.1 \times 10^{-3}(62)$ & $1.4 \times 10^{-3}$ \\
\hline (3) $10 \mu \mathrm{M}$ ATP & $1.5(43)$ & $0.11(17)$ & $9.7 \times 10^{-3}(40)$ & $2.8 \times 10^{-3}$ \\
\hline (4) $0.10 \mathrm{mM} \mathrm{ATP}$ & $1.04(74)$ & $5.9 \times 10^{-2}(26)$ & -- & $6.7 \times 10^{-3}$ \\
\hline (5) $1.0 \mathrm{mM}$ ATP & $0.98(80)$ & $7.1 \times 10^{-2}(20)$ & -- & $8.0 \times 10^{-3}$ \\
\hline \multicolumn{5}{|c|}{ Figure S9d: step C at $100 \mathrm{mM}$ MES, $300 \mathrm{mM} \mathrm{KCl,} \mathrm{pH} \mathrm{5.6,} 200 \mathrm{~s}, 0-4.0 \mathrm{mM}$ reductants } \\
\hline (1) no reductants & -- & -- & $1.2 \times 10^{-3}(100)$ & -- \\
\hline (2) $4.0 \mathrm{mM} \mathrm{GSH}$ & $1.57(11)$ & $0.10(10)$ & $1.9 \times 10^{-3}(79)$ & $5.8 \times 10^{-4}$ \\
\hline (3) $4.0 \mathrm{mM} \mathrm{NADH}$ & $1.9(18)$ & $9.4 \times 10^{-2}(10)$ & $1.9 \times 10^{-3}(72)$ & $1.6 \times 10^{-3}$ \\
\hline (4) $4.0 \mathrm{mM} \mathrm{AscH}$ & $1.30(40)$ & $0.14(15)$ & $3.9 \times 10^{-3}(45)$ & $2.5 \times 10^{-3}$ \\
\hline
\end{tabular}

Table continues at the next page 


\begin{tabular}{|c|c|c|c|c|}
\hline \multirow[t]{2}{*}{ Conditions } & \multicolumn{4}{|c|}{ Kinetic Parameters } \\
\hline & $k_{1}, \mathbf{s}^{-1}(\%)^{b}$ & $k_{2}, \mathrm{~s}^{-1}(\%)^{b}$ & $k_{3}, \mathrm{~s}^{-1}(\%)^{b}$ & $k \mathrm{Fe}, \mathbf{s}^{-1 c}$ \\
\hline \multicolumn{5}{|c|}{ Figure S9e: step $\mathbf{C}$ at $100 \mathrm{mM}$ MES, $300 \mathrm{mM} \mathrm{KCl}, \mathrm{pH} 5.6,0.10 \mathrm{mM}$ citrate, varied time } \\
\hline (1) $15 \mathrm{~s}$ & $1.3(24)$ & $0.11(24)$ & $3.9 \times 10^{-3}(52)$ & $1.8 \times 10^{-2}$ \\
\hline (2) $60 \mathrm{~s}$ & $1.1(55)$ & $0.12(22)$ & $1.0 \times 10^{-2}(23)$ & $1.3 \times 10^{-2}$ \\
\hline (3) $120 \mathrm{~s}$ & $1.2(73)$ & $0.19(15)$ & $3.9 \times 10^{-2}(9)$ & $1.1 \times 10^{-2}$ \\
\hline $\begin{array}{c}\text { (4) } 15 \mathrm{~s} \\
1.0 \mathrm{mM} \mathrm{AscH}\end{array}$ & $1.2(72)$ & $0.22(17)$ & $3.1 \times 10^{-2}(11)$ & $8.5 \times 10^{-2}$ \\
\hline \multicolumn{5}{|c|}{ Figure S9f: step C at $100 \mathrm{mM}$ MES, $140 \mathrm{mM} \mathrm{NaCl}, \mathrm{pH} 5.6,200 \mathrm{~s}$, serum components } \\
\hline (1) no additions & -- & -- & $4.2 \times 10^{-4}(100)$ & -- \\
\hline (2) $1.0 \mathrm{mM}$ glycine & $1.6(7)$ & $4.3 \times 10^{-2}(6)$ & $6.5 \times 10^{-4}(87)$ & $3.6 \times 10^{-4}$ \\
\hline (3) $1.8 \mathrm{mM}$ L-lactate & $0.98(11)$ & $0.12(5)$ & $1.3 \times 10^{-3}(84)$ & $5.8 \times 10^{-4}$ \\
\hline (4) $0.10 \mathrm{mM}$ citrate & $0.60(50)$ & $0.10(19)$ & $3.9 \times 10^{-3}(31)$ & $3.5 \times 10^{-3}$ \\
\hline $\begin{array}{c}\text { (5) serum } \\
\text { ultrafiltrate }^{d}\end{array}$ & $1.05(55)$ & $0.14(21)$ & $5.5 \times 10^{-3}(24)$ & $4.0 \times 10^{-3}$ \\
\hline
\end{tabular}

${ }^{a}$ Reaction conditions correspond to Figure S9, and numbers in parentheses correspond to the curve numbers in this figure. All the measurements were performed at $295 \pm 1 \mathrm{~K} .{ }^{b}$ Kinetics of step D were fitted (Figure S9) with one to three parallel first order processes, the corresponding rate constants $\left(k_{1}-k_{3}\right)$ are shown. Final BLI signals were set to zero during calculations. Numbers in parentheses show the relative contributions (\%) of each process into the total decrease of BLI signal. ${ }^{c}$ Estimated first-order rate constant of $\mathrm{Fe}(\mathrm{III})$ removal in step $\mathbf{C}$. Estimations are based on the following equation: $k=[\ln (1 /(1-$ apoTf $)] / t$, where apoTf is the molar part of apoTf (relative to total Tf) formed under the endosomal condition (corresponds to the number is parentheses in the second column from left, divided by 100), and $t$ (s) is the reaction time under endosomal conditions. This is the lowest estimate of the total rate of $\mathrm{Fe}(\mathrm{III})$ removal, since it does not take into account the formation of partially Fe-depleted Tf-TfR 1 adducts in the endosomal step. ${ }^{d}$ Ultrafiltrate $(<3 \mathrm{kDa}$ ) of human serum (Sigma H4522) was obtained by centrifugal membrane filtration (Nanosep 3K Omega from Pall Life Sciences; $30 \mathrm{~min}$ at 14,000 $\mathrm{g}$ at $277 \mathrm{~K}$ ) and acidified to $\mathrm{pH}=5.6$ with $100 \mathrm{mM}$ of MES (free acid). 


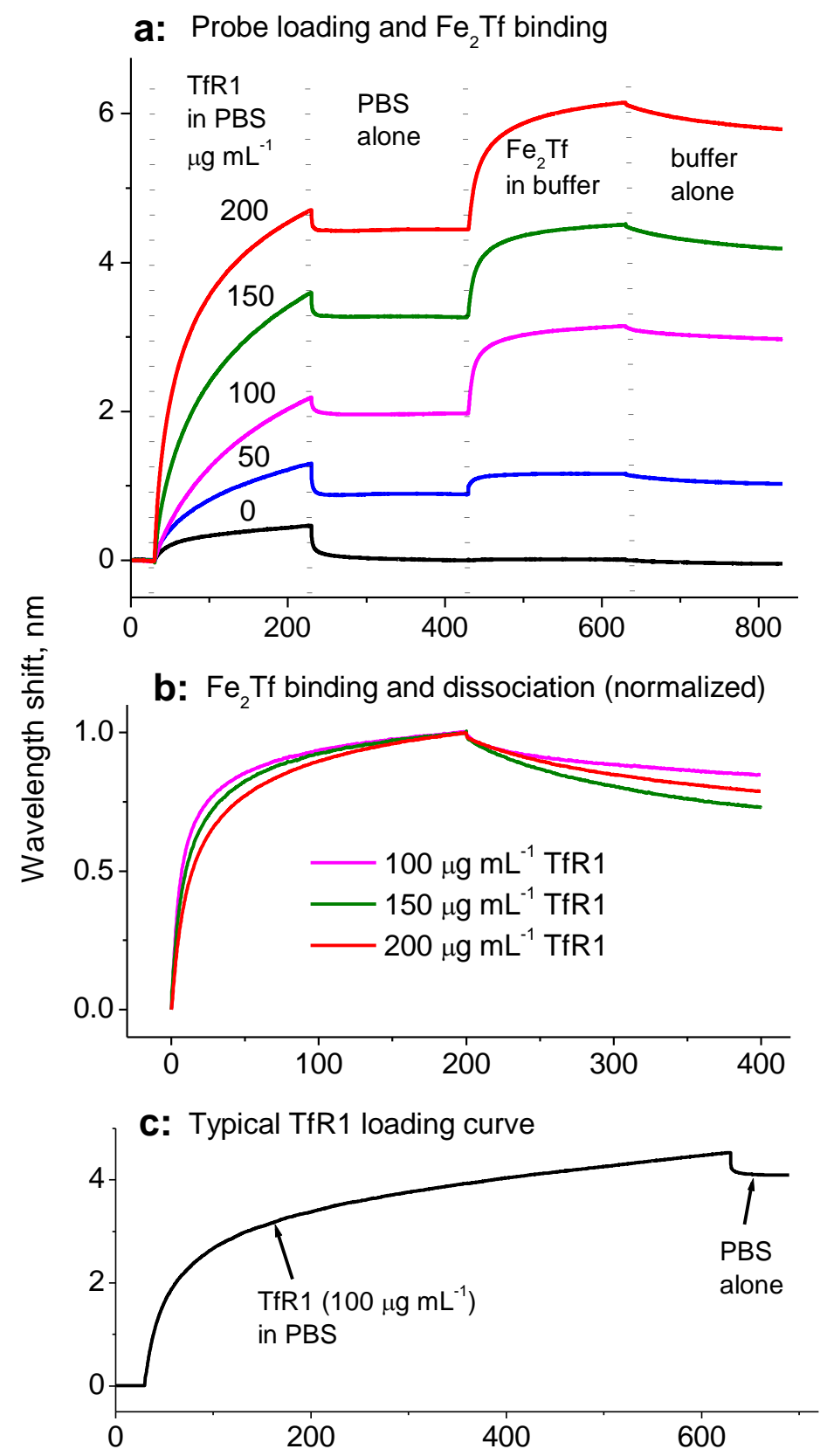

Figure S1. Optimization of loading conditions of Ni(II)-NTA probe with recombinant human His6-tagged TfR1 (4.0 $\mu \mathrm{L}$ of solution in PBS, $295 \mathrm{~K}$ ). a) Effect of TfR1 concentration on probe loading density within $200 \mathrm{~s}$, and on the subsequent binding and dissociation of $\mathrm{Fe}_{2} \mathrm{Tf}(1.0 \mu \mathrm{M}$ in $20 \mathrm{mM}$ HEPES, $25 \mathrm{mM} \mathrm{NaHCO} 3,140 \mathrm{mM} \mathrm{NaCl}$, pH 7.4). b) Expanded view of $\mathrm{Fe}_{2} \mathrm{Tf}$ binding and dissociation curves at different TfR1 loading densities. c) Typical loading curve of a Ni(II)NTA probe with TfR1 for Tf cycle studies (the probe was subsequently used at least 12 times without re-loading, see Figure S3 and Table S1). 


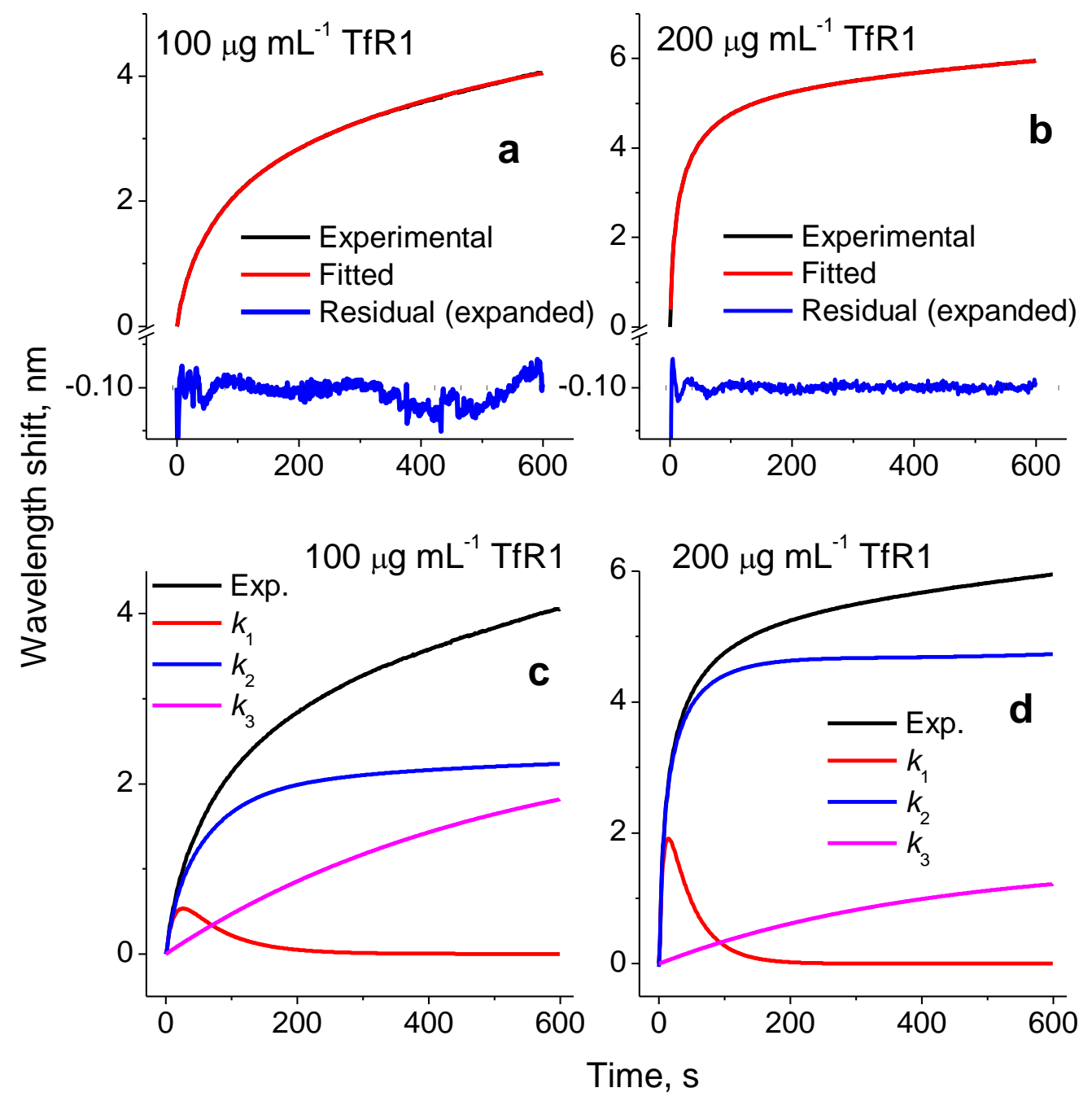

Figure S2. Typical results of kinetic analyses of Ni(II)-NTA probe loading with TfR1 (performed with ProKineticist software). a) and b) Experimental and fitted loading curves at the optimal (100 $\mathrm{g} \mathrm{mL}^{-1}$, see Figure S1) and high $\left(200 \mu \mathrm{g} \mathrm{mL}^{-1}\right)$ concentrations of TfR1. c) and d) Deconvolution of the experimental kinetic curves into two sequential $\left(k_{1}\right.$ and $\left.k_{2}\right)$ and one parallel $\left(k_{3}\right)$ first-order steps. Calculated values of the rate constants were as follows: for $100 \mu \mathrm{g} \mathrm{mL}^{-1}$ TfR $1, k_{1}=7.8 \times 10^{-2} \mathrm{~s}^{-1}, k_{2}=1.5 \times 10^{-2} \mathrm{~s}^{-1}, k_{3}=2.0 \times 10^{-3} \mathrm{~s}^{-1}$; and for $200 \mu \mathrm{gL}^{-1} \mathrm{TfR} 1, k_{1}=$ $1.55 \times 10^{-1} \mathrm{~s}^{-1}, k_{2}=2.9 \times 10^{-2} \mathrm{~s}^{-1}, k_{3}=2.0 \times 10^{-3} \mathrm{~s}^{-1}$. Note that the values of $k_{1}$ and $k_{2}$ are directly proportional to the concentration of TfR1, while $k_{3}$ is concentration-independent. Assignment of the kinetic steps is as follows: (i) red lines in (c,d) correspond to the formation and decay of monomeric His6-TfR1 bound to Ni(II) ions at the probe surface; (ii) blue lines in (c,d) correspond to the formation of dimeric His6-TfR1 bound to $\mathrm{Ni}$ (II) ions at the probe surface; and (iii) magenta lines in (c,d) correspond to non-specific protein binding to the probe surface. 


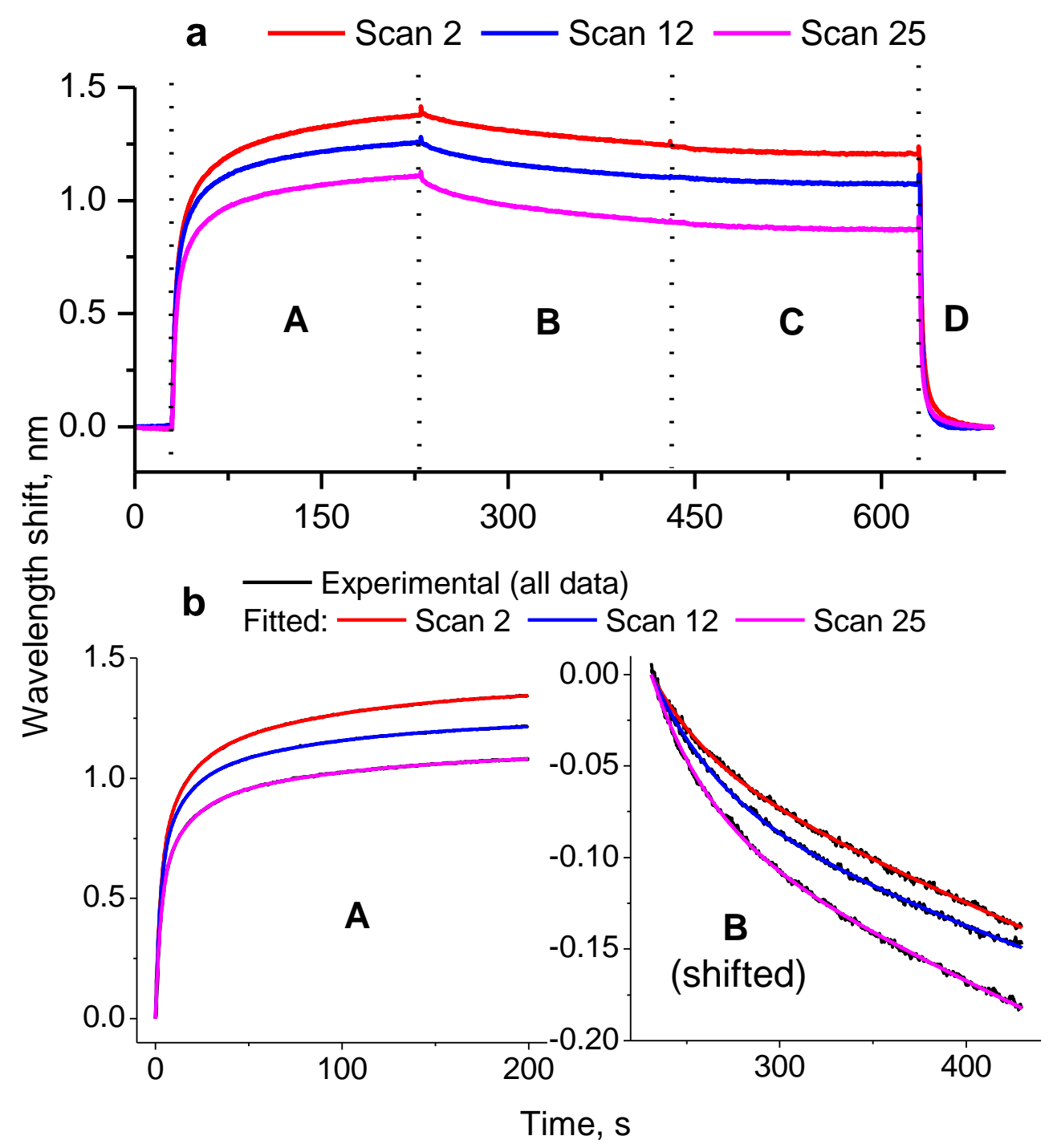

Figure S3. Effect of repeated scans at the same TfR1-loaded probe on Tf cycle. a) Full Tf cycle at $1.0 \mu \mathrm{M} \mathrm{Fe} 2 \mathrm{Tf}$ (see Figures 1a and 2a in the main text for designations of the steps and experimental conditions). b) Overlays and kinetic analyses of the steps $\mathbf{A}$ and $\mathbf{B}$ (see Table S1 for calculated rate constants). 


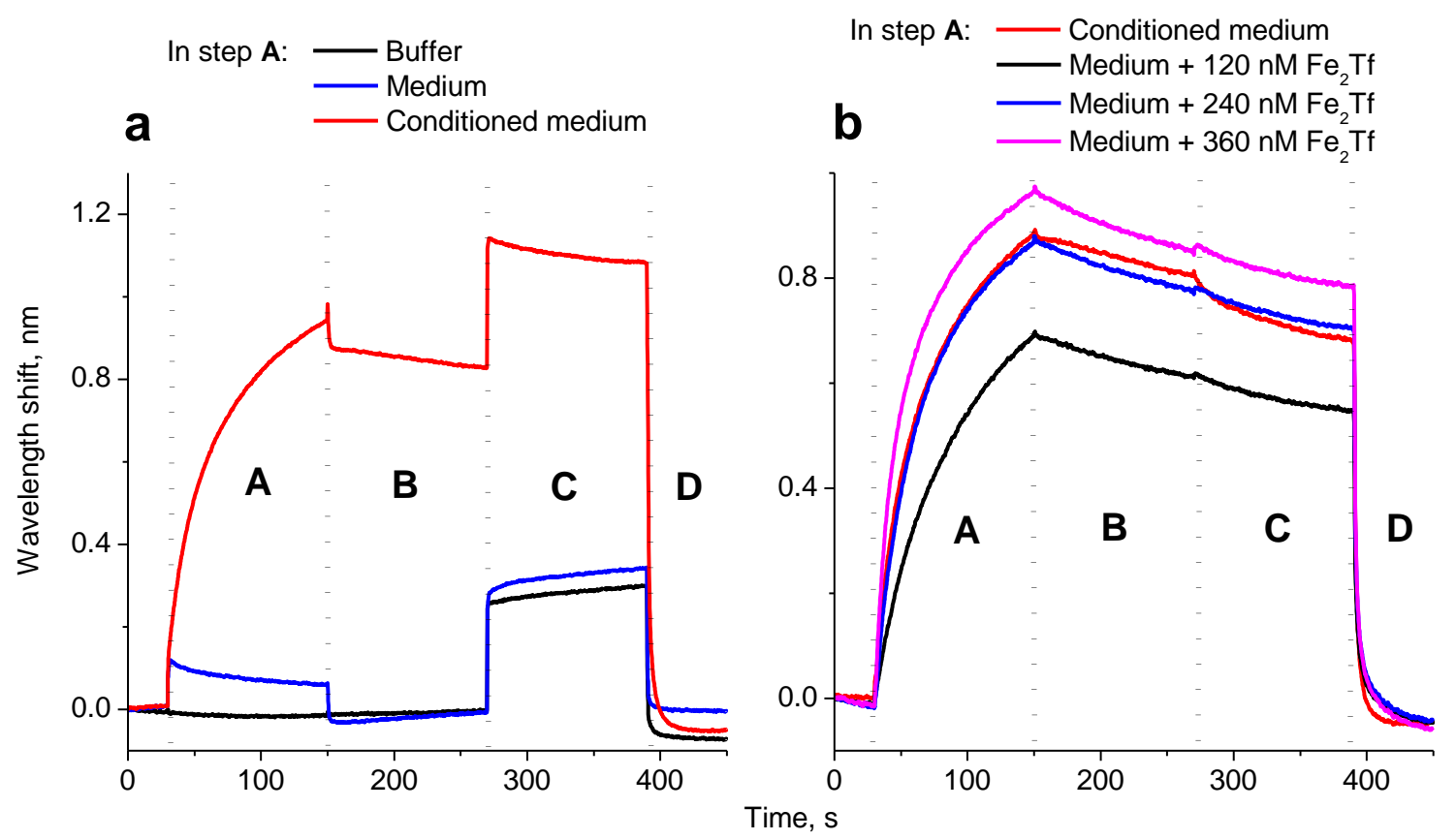

Figure S4. Use of BLI to measure the release of Tf by HepG2 cells (see Methods for details), designations of the steps A-D correspond to Figures 1a and 2 in the main text. a) Comparison of

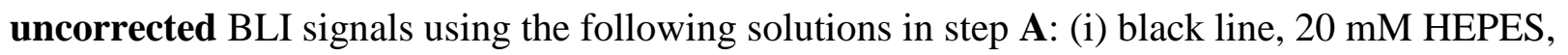
$25 \mathrm{mM} \mathrm{NaHCO}_{3}, 140 \mathrm{mM} \mathrm{NaCl}, 2.0 \mathrm{mg} \mathrm{mL}^{-1}$ BSA, pH 7.40, (ii) blue line, undiluted cell culture medium before culturing HepG2 cells; (iii) red line, the same medium after culturing the cells. b) Comparison of blank-corrected BLI signals, using the blue line in (a) as a blank and the following solutions in step A: (i) red line, cell culture medium after culturing HepG2 cells; (ii) black line, the same medium before culturing the cells, with $120 \mathrm{nM} \mathrm{Fe} 2 \mathrm{Tf}$ added; (iii) blue line, same as (ii), with $240 \mathrm{nM} \mathrm{Fe} 2 \mathrm{Tf}$ added; and (iv), magenta line, same as (ii) with $360 \mathrm{nM} \mathrm{Tf}$ added. Note the linear dependence of the initial rate of $\mathrm{Fe}_{2} \mathrm{Tf}$ binding to the probe on its concentration in the medium (consistent with the data of Table S1), which was used to create a calibration curve for the determination of $\mathrm{Fe}_{2} \mathrm{Tf}$ concentration in cell culture medium after culturing the cells. For all experiments, the following buffer was used in steps $\mathbf{B}$ and $\mathbf{D}: 20 \mathrm{mM}$ HEPES, $25 \mathrm{mM} \mathrm{NaHCO}, 140 \mathrm{mM} \mathrm{NaCl}, 2.0 \mathrm{mg} \mathrm{mL}^{-1} \mathrm{BSA}$, pH 7.40; and the following buffer was used in step C: $100 \mathrm{mM} \mathrm{MES}, 300 \mathrm{mM} \mathrm{KCl}, 0.50 \mathrm{mM}$ citrate, $2.0 \mathrm{mg} \mathrm{mL}^{-1} \mathrm{BSA}, \mathrm{pH}=$ 5.60. Typical measured concentrations of human $\mathrm{Fe}_{2} \mathrm{Tf}$ in the conditioned medium were $230 \pm 30 \mathrm{nM}(n=6)$. 

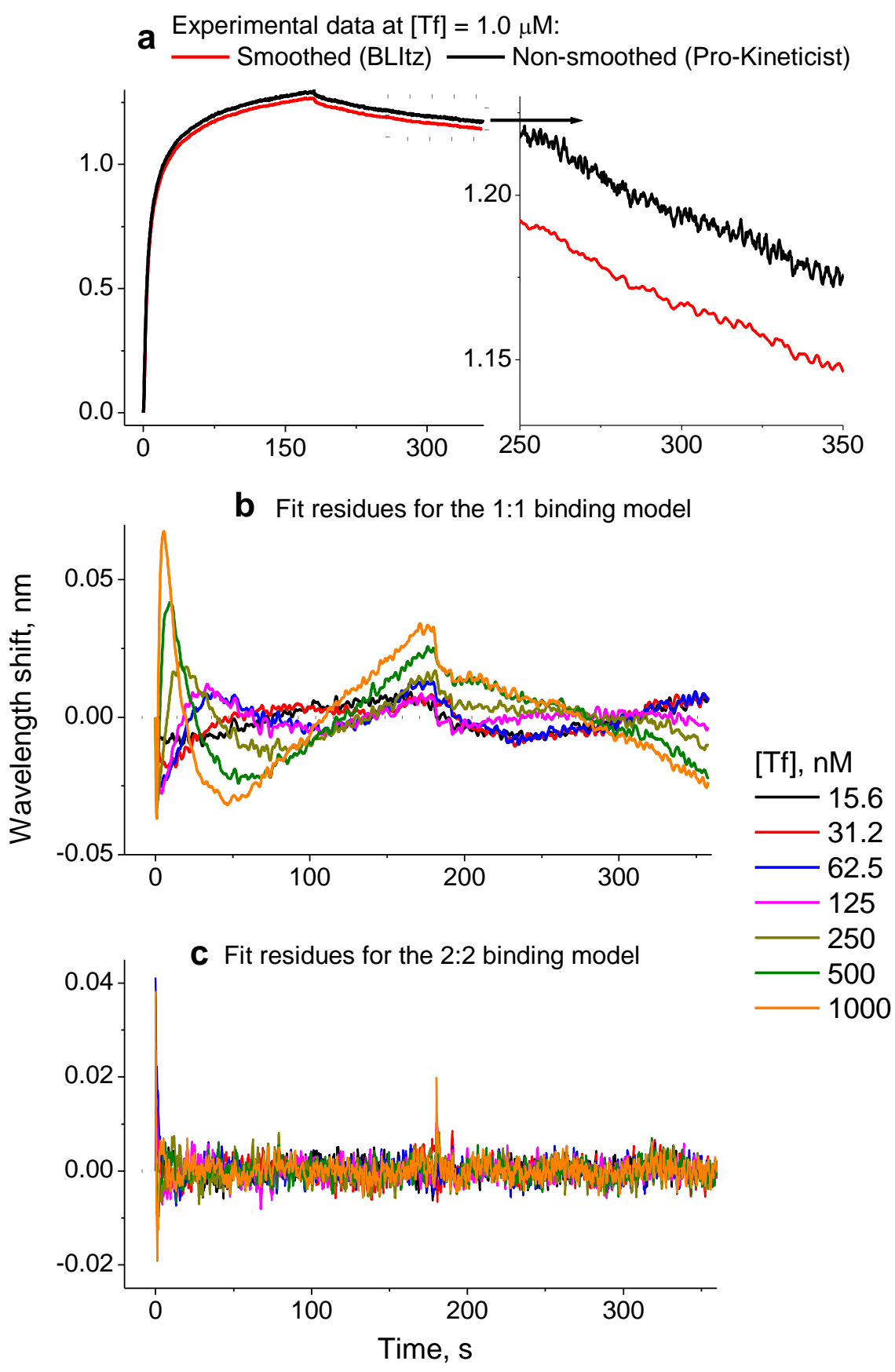

Figure S5. Details of kinetic analyses of steps $\mathbf{A}$ and $\mathbf{B}$ of Tf cycle (Figure 3 in the main text) using BLItz ${ }^{\mathrm{S} 3}$ and ProKineticist ${ }^{\mathrm{S} 5}$ software. a) Typical changes in experimental curves that are caused by data smoothing in BLItz software (original non-smoothed data were used in ProKineticist software). ${ }^{\mathrm{S} 5} \mathbf{b}$ ) and c) Concentration-dependent fit residues for the 1:1 (Blitz) ${ }^{\mathrm{S} 3}$ and 2:2 (ProKineticist) ${ }^{\mathrm{S} 5}$ binding models, respectively. 

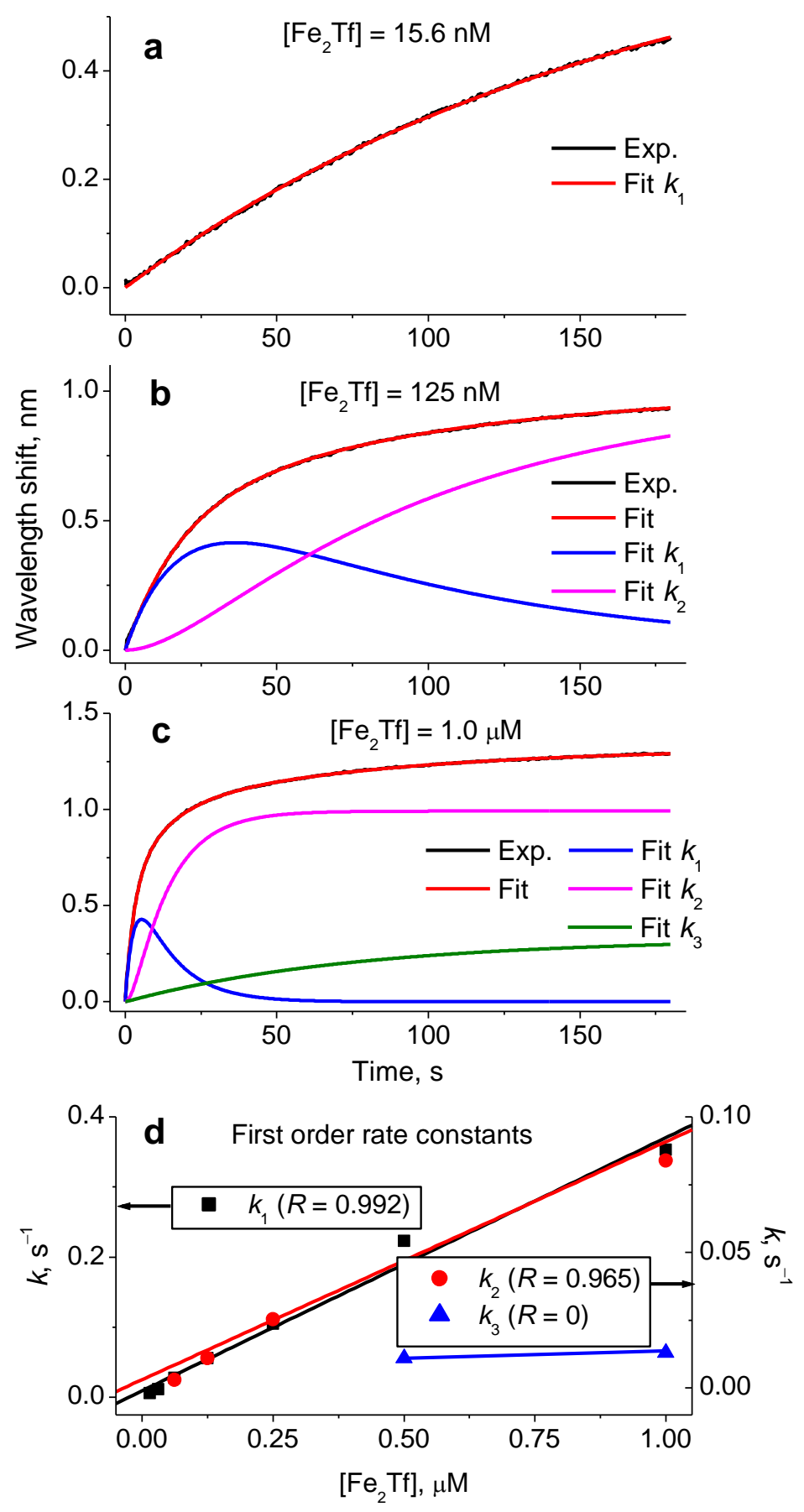

Figure S6. Kinetic fitting of the step $\mathbf{A}$ in Tf cycle (Figure $3 b$ in the main text) with a combination of one, two or three first-order steps. a)-c) Application of various kinetic models for low, intermediate and high $\mathrm{Fe}_{2} \mathrm{Tf}$ concentrations. d) Concentration dependence of the first order rate constants (see the detailed description of kinetic analyses at pp. 3-4, and the calculated values of rate constants in Table S1). 

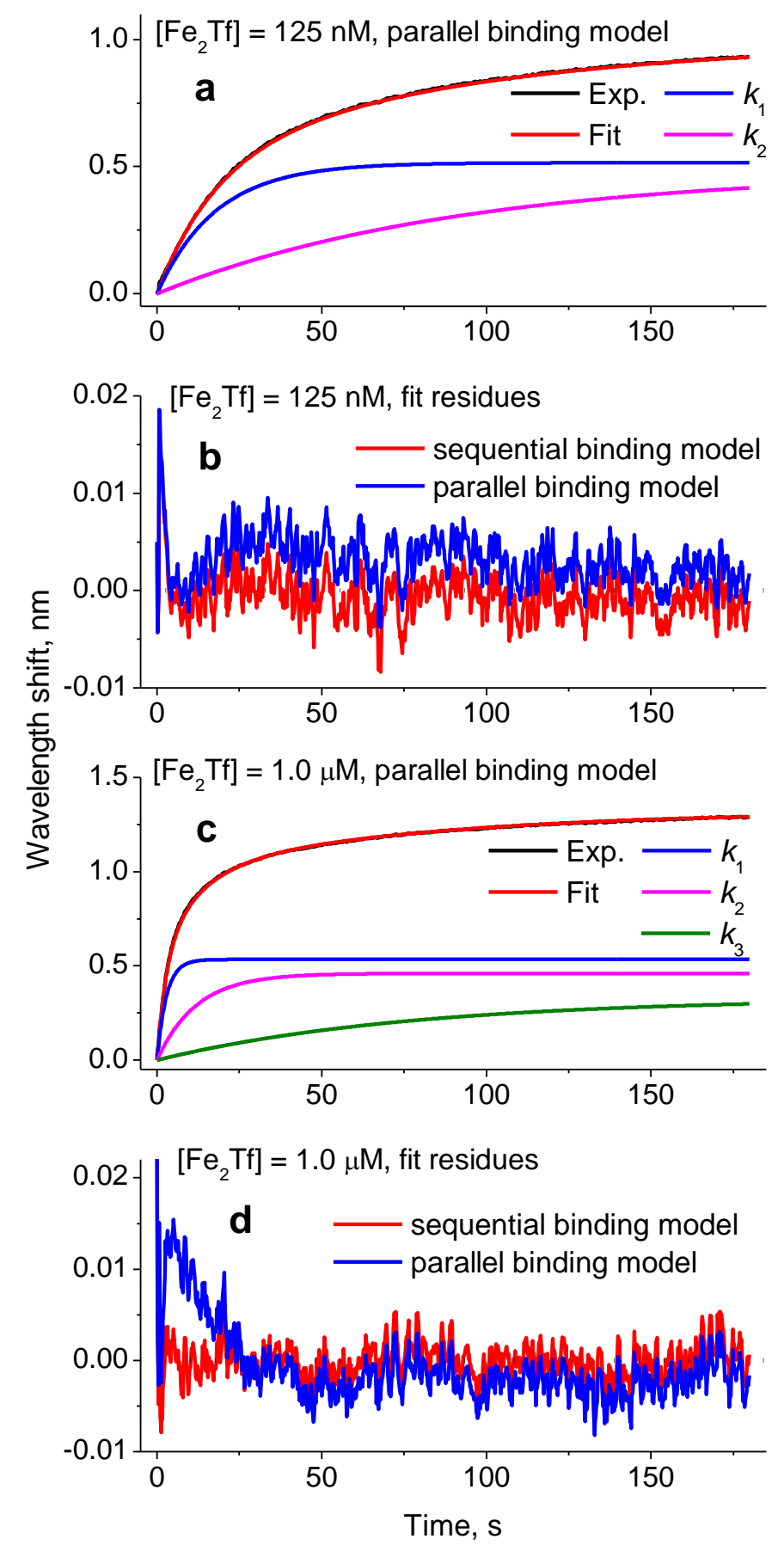

Figure S7. Fitting of the kinetic curves for step $\mathbf{A}$ of $\mathrm{Fe}_{2} \mathrm{Tf}$ binding to TfR1 at $\mathrm{pH} 7.4$ (20 mM HEPES, $\left.25 \mathrm{mM} \mathrm{NaHCO}_{3}, 140 \mathrm{mM} \mathrm{NaCl}\right)$ with two $\left(\left[\mathrm{Fe}_{2} \mathrm{Tf}\right]=125 \mathrm{nM},(\mathbf{a}, \mathbf{b})\right)$ or three $\left(\left[\mathrm{Fe}_{2} \mathrm{Tf}\right]=\right.$ $1.0 \mu \mathrm{M},(\mathbf{c}, \mathbf{d}))$ parallel steps (using the rate constants listed in Table S1) and comparison of fit residues for parallel and sequential binding models. 

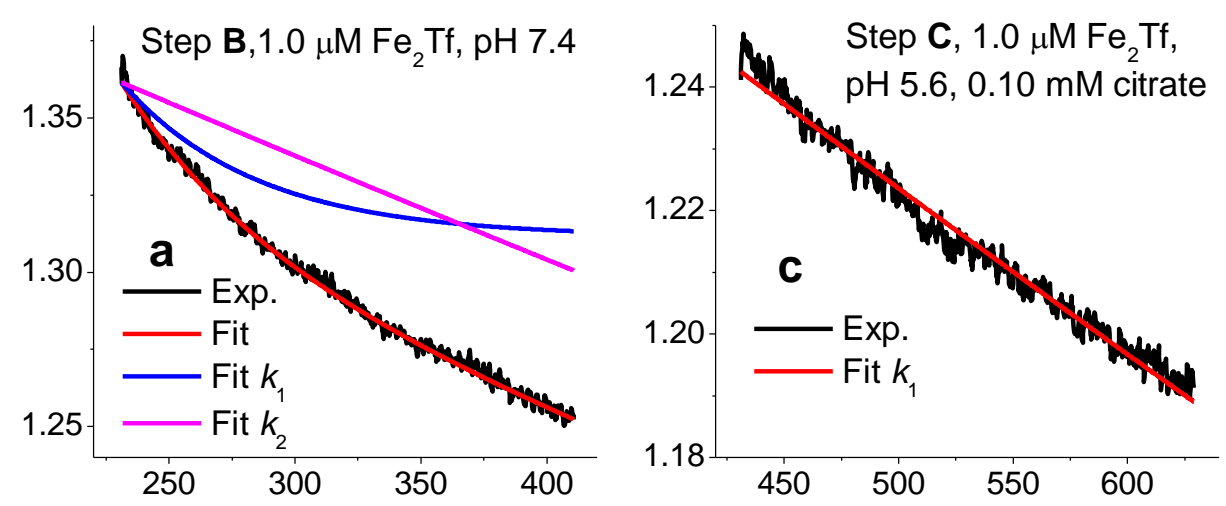

Step B, $1.0 \mu \mathrm{M} \mathrm{Fe} \mathrm{Tf}_{2}$

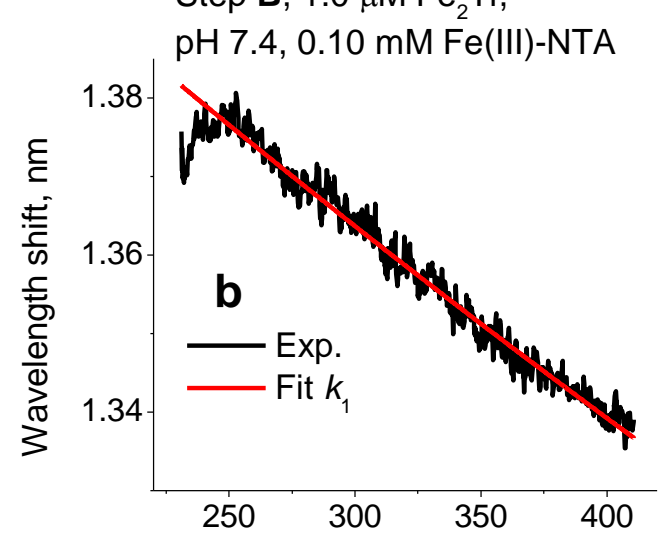

Step B, $1.0 \mu \mathrm{M}$ apoTf, pH 5.6
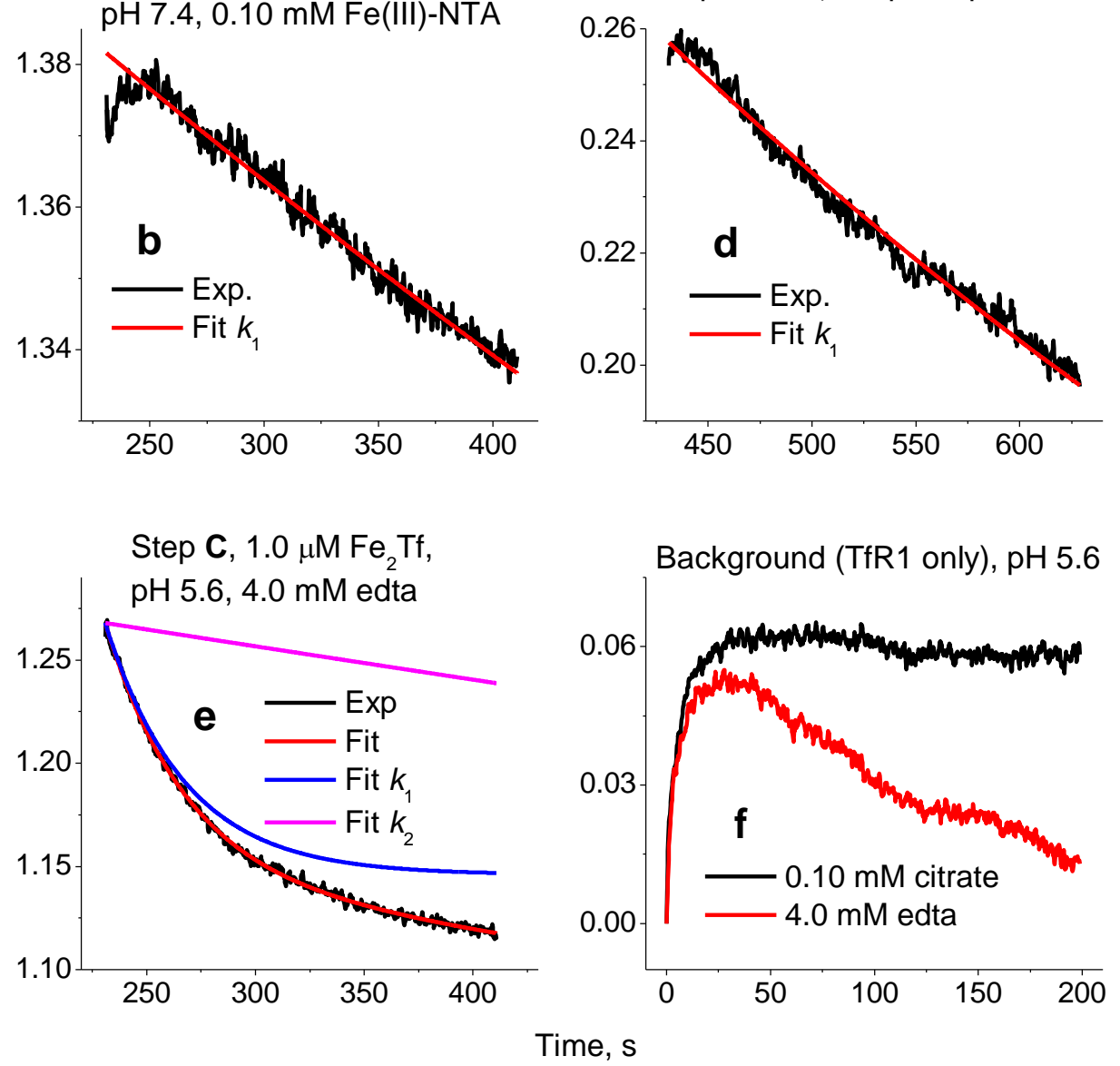

Figure S8. Typical kinetics of the dissociation steps $\mathbf{B}$ and $\mathbf{C}$ of the Tf cycle (detailed description is given at pp. 3-4). Buffers used: (i) $20 \mathrm{mM} \mathrm{HEPES,} 25 \mathrm{mM} \mathrm{NaHCO} 3,140 \mathrm{mM}$ $\mathrm{NaCl}, \mathrm{pH}$ 7.4; and (ii) $100 \mathrm{mM} \mathrm{MES}, 300 \mathrm{mM} \mathrm{KCl}, \mathrm{pH}$ 5.6. Calculated rate constants (ProKineticist software): (a) $k_{1}=2.3 \times 10^{-2} \mathrm{~s}^{-1}, k_{2}=4.3 \times 10^{-4} \mathrm{~s}^{-1}$; (b) $k_{1}=3.8 \times 10^{-4} \mathrm{~s}^{-1}$; (c) $k_{1}$ $=2.2 \times 10^{-4} \mathrm{~s}^{-1}$; (d) $k_{1}=2.4 \times 10^{-4} \mathrm{~s}^{-1}$; and (e) $k_{1}=2.6 \times 10^{-2} \mathrm{~s}^{-1}, k_{2}=3.3 \times 10^{-4} \mathrm{~s}^{-1}$. 


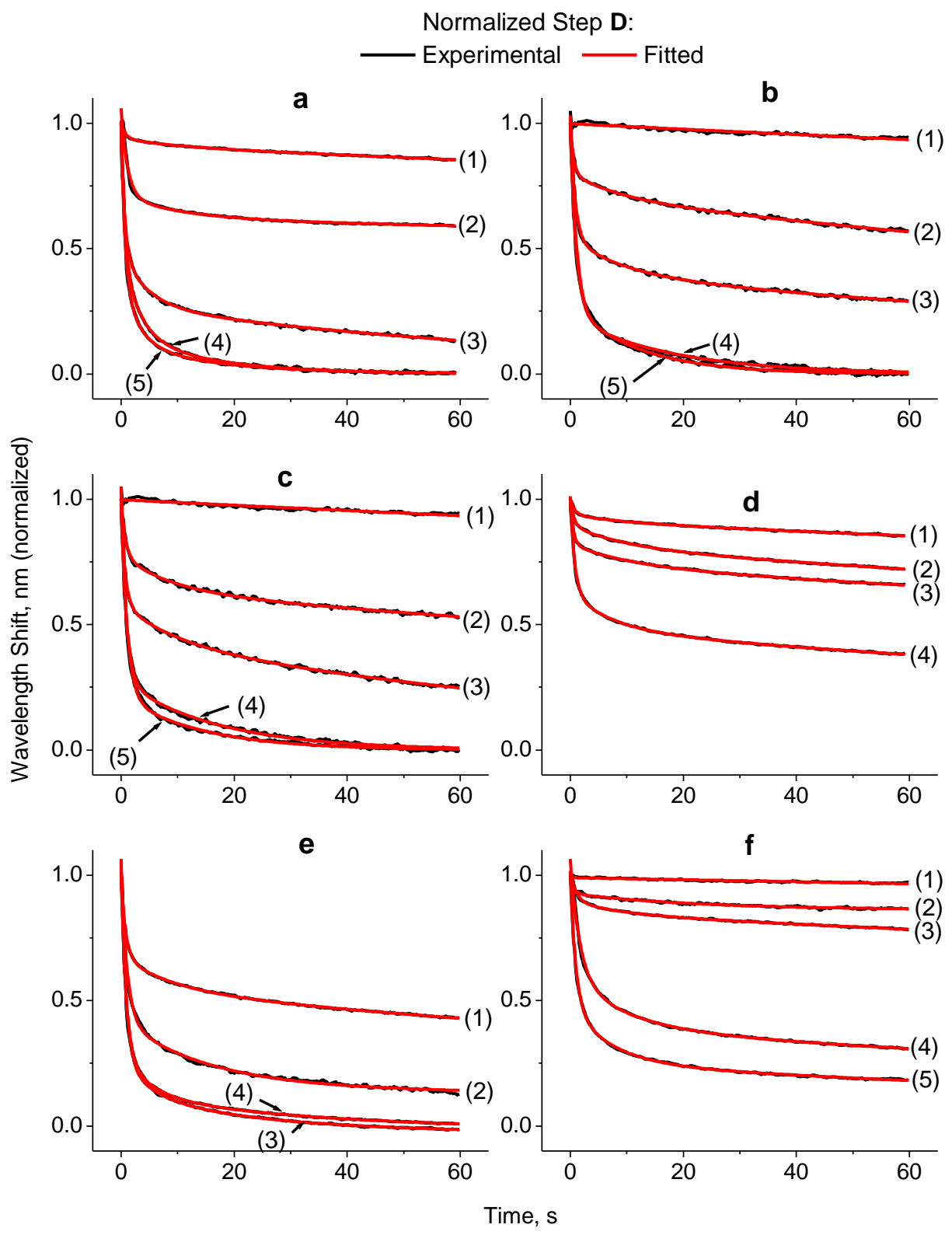

Figure S9. Typical kinetics of post-endosomal dissociation of Tf from TfR1 (step D in Figures 1a and 2; (295 \pm 1$)$ K). a)-f) Variations of conditions of step C; see Table S2 for details.

Experimental kinetic curves (black lines) were fitted with a combination of one to three parallel first order processes using ProKineticist ${ }^{\mathrm{S} 5}$ software (red lines; calculated rate constants are listed in Table S2). Buffer used in step D: $20 \mathrm{mM}$ HEPES, $25 \mathrm{mM} \mathrm{NaHCO}_{3}, 140 \mathrm{mM} \mathrm{NaCl}$, pH = 7.40. The BLI signals at the start of each kinetic curve were normalized to $1.0 \mathrm{~nm}$ for easy comparison (i.e., $100 \%$ removal of Tf from the probe corresponds to $0.0 \mathrm{~nm}$ ). 